\title{
Editorial comment on "Reimplantation of the upper lobe bronchus after lower sleeve lobectomy or bilobectomy: long-term results" by Maurizi et al.
}

\author{
Corinna Ludwig \\ Department of Thoracic Surgery, Florence Nightingale Hospital, Düsseldorf, Germany \\ Correspondence to: Corinna Ludwig, MD. Department of Thoracic Surgery, Florence Nightingale Hospital, Kreuzbergstr. 79 , 40489 Düsseldorf, \\ Germany. Email: ludwigc@kaiserswerther-diakonie.de. \\ Provenance: This is an invited Editorial commissioned by the Section Editor Min Zhang (Department of Thoracic Oncology, The First Affiliated \\ Hospital of Chongqing Medical University, Chongqing, China). \\ Comment on: Maurizi G, Ciccone AM, Vanni C, et al. Reimplantation of the upper lobe bronchus after lower sleeve lobectomy or bilobectomy: Long- \\ term results. Eur J Cardiothorac Surg 2018;53:1180-5.
}

Submitted Oct 23, 2018. Accepted for publication Dec 06, 2018.

doi: $10.21037 /$ jtd.2018.12.32

View this article at: http://dx.doi.org/10.21037/jtd.2018.12.32

The advantage of sleeve lobectomy over pneumonectomy in terms of postoperative morbidity and mortality in centrally located lung cancer is well established (1-5). The incidence of sleeve procedures still varies largely world-wide. In the above mentioned article by Maurizi et al. long-term results after complex tracheobronchial reconstruction are presented together with technical aspects (6).

For this purpose, the authors retrospectively reviewed 28 (9\%) patients over a period of 26 years [1989-2015] submitted to sleeve lobectomy or bilobectomy with Y-sleeve resection and reconstruction. During the same period 312 sleeve lobectomies were performed for centrally located tumours. The technical difficulty of this operation is described as due to size discrepancy of the orifices, proximity of the pulmonary artery, poor exposure of the mediastinal side of the anastomosis and proximity to the segment division of the upper lobe once it has been divided.

Surgical approach was a lateral muscle-sparing thoracotomy after standard preoperative clinical and functional evaluation. Fresh frozen section of the bronchus was performed in all patients to validate radicality. The authors recommend anastomotic reconstruction by interrupted 4-0 absorbable sutures in an outside-to-in fashion to avoid torsion. According to Maurizi et al., this compensates best large calibre discrepancies. On the left side where there is less calibre difference partial continuous running suture was sometimes used. An intercostal flap was used in all cases to protect the anastomosis (7). Maurizi et al. recommend inhalation of low-dose steroids to reduce the anti-oedema effect, secretion retention and risk of granuloma formation. Follow-up bronchoscopy was performed 1, 3 and 6 months and then once a year for 5 years.

Two patients $(7 \%)$ received induction chemotherapy for preoperative $\mathrm{N} 2$ disease. R0 resection rate was $100 \%$. Overall morbidity rate was $25 \%(7 / 28)$. Rate of postoperative bronchopleural fistula was $2.8 \%$. The rate of postoperative bronchial complications vary in the literature between $0-8 \%$ (8). Major complications (3/28) in this study included myocardial infarction, pleural empyema due to bronchopleural fistula and one anastomotic stenosis treated by laser. The patient with a bronchopleural fistula died of sepsis postoperatively. Postoperative adjuvant chemotherapy was given in 9 patients.

Mean long-team follow-up was 46 months (2-117 months). The recurrence rate was $32 \%$, of which 2 (9\%) were loco-regional. No anastomotic recurrence. The 3 - and 5-year OS and DFS survival rates were $76.3 \%$ and $55.1 \%$ and $68.7 \%$ and $62.9 \%$ respectively.

Technical aspects of complex bronchial reconstruction are described. Thoracotomy is preferred over videoassisted approach for better exposure. Interrupted suture of the bronchial anastomosis is recommended. Yet favourable results have been seen with complete double 
armed continuous running suture of the anastomosis with absorbable material and minimally invasive approaches (9-12). Bronchial size discrepancy of the orifices can be adapted either over the whole bronchial circumference or by using the membranous portion of the bronchial circumference to adapt size difference. Surgical technique and protection of the anastomosis is an important issue $(7,13)$. Some authors postulate that covering an anastomosis is unnecessary (8). Whereas others prefer protecting the anastomosis, especially after induction therapy (14). Bronchial healing can be supported by a tension free anastomosis (pericardial release), radical resection (R0), and avoiding bronchial infection for example with local inhalation of antibiotics (10). Maurizi et al. describe retention of secretion after Y-sleeve resection, but postoperative bronchoscopy regimen to assure bronchial healing is not documented (15).

Long-term results were excellent in stage I and II NSCLC, which confirms oncological reliability of this surgical procedure, especially as no local recurrence at the level of the bronchial reconstruction was observed. In stage III, the results were not as good but due to the small number of patients care must be taken with over interpretation.

In conclusion, even complex sleeve procedures should be considered whenever technically and oncologically feasible. Short- and long-term results plead in favour.

Finally, the limitations of the data used for the published paper by Maurizi et al. should be mentioned. These include the small sample size over a long period of time and the retrospective nature of the data.

\section{Acknowledgements}

None.

\section{Footnote}

Conflicts of Interest: The author has no conflicts of interest to declare.

\section{References}

1. Gómez-Caro A, Garcia S, Reguart N, et al. Determining the appropriate sleeve lobectomy versus pneumonectomy ratio in central non-small cell lung cancer patients: an audit of an aggressive policy of pneumonectomy avoidance. Eur J Cardiothorac Surg 2011;39:352-9.
2. Ferguson MK, Lehman AG. Sleeve lobectomy or pneumonectomy: optimal management strategy using decision analysis techniques. Ann Thorac Surg 2003;76:1782-8.

3. Deslauriers J, Gregoire J, Jacques LF, et al. Sleeve lobectomy versus pneumonectomy for lung cancer: a comparative analysis of survival and sites or recurrences. Ann Thorac Surg 2004;77:1152-6; discussion 1156.

4. Yoshino I, Yokoyama H, Yano T, et al. Comparison of the surgical results of lobectomy with bronchoplasty and pneumonectomy for lung cancer. J Surg Oncol 1997;64:32-5.

5. Ludwig C, Stoelben E, Olschewski M, et al. Comparison of morbidity, 30-day mortality, and long-term survival after pneumonectomy and sleeve lobectomy for non-small cell lung carcinoma. Ann Thorac Surg 2005;79:968-73.

6. Maurizi G, Ciccone AM, Vanni C, et al. Reimplantation of the upper lobe bronchus after lower sleeve lobectomy or bilobectomy: long-term results. Eur J Cardiothorac Surg 2018;53:1180-5.

7. Rendina EA, Venuta F, Ricci P, et al. Protection and revascularization of bronchial anastomoses by the intercostal pedicle flap. J Thorac Cardiovasc Surg 1994;107:1251-4.

8. Storelli E, Tutic M, Kestenholz P, et al. Sleeve resections with unprotected bronchial anastomoses are safe even after neoadjuvant therapy. Eur J Cardiothorac Surg 2012;42:77-81.

9. Aigner C, Jaksch P, Seebacher G, et al. Single running suture--the new standard technique for bronchial anastomoses in lung transplantation. Eur J Cardiothorac Surg 2003;23:488-93.

10. Ludwig C, Riedel R, Schnell J, et al. Inhalation with Tobramycin to improve healing of tracheobronchial reconstruction. Eur J Cardiothorac Surg 2009;35:797-800; discussion 800.

11. Ohata $\mathrm{K}$, Zhang J, Ito $\mathrm{S}$, et al. Thoracoscopic bronchoplasty using continuous sutures in complete monitor view. Ann Thorac Surg 2014;98:1132-3.

12. Huang J, Li S, Hao Z, et al. Complete video-assisted thoracoscopic surgery (VATS) bronchial sleeve lobectomy. J Thorac Dis 2016;8:553-74.

13. Venuta F, Diso D, Anile M, et al. Techniques of protection and revascularization of the bronchial anastomosis. J Thorac Dis 2016;8:S181-5.

14. Hollaus PH, Wilfing G, Wurnig PN, et al. Risk factors 
for the development of postoperative complications after bronchial sleeve resection for malignancy: a univariate and multivariate analysis. Ann Thorac Surg 2003;75:966-72.

Cite this article as: Ludwig C. Editorial comment on "Reimplantation of the upper lobe bronchus after lower sleeve lobectomy or bilobectomy: long-term results" by Maurizi et al. J Thorac Dis 2018;10(12):6427-6429. doi: 10.21037/ jtd.2018.12.32
15. Ludwig C, Stoelben E. A new classification of bronchial anastomosis after sleeve lobectomy. J Thorac Cardiovasc Surg 2012;144:808-12. 